\title{
Low molecular weight heparin may benefit nephrotic remission in steroid-sensitive nephrotic syndrome via inhibiting elastase
}

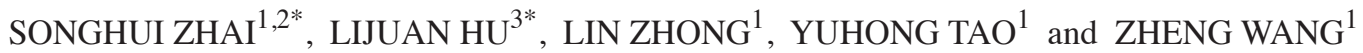 \\ ${ }^{1}$ Department of Pediatrics, West China Second University Hospital, Sichuan University; ${ }^{2}$ Key Laboratory of \\ Birth Defects and Related Diseases of Women and Children (Sichuan University), Ministry of \\ Education; ${ }^{3}$ Department of Immunology, West China School of Basic Medical Sciences and \\ Forensic Medicine, Sichuan University, Chengdu, Sichuan 610041, P.R. China
}

Received March 28, 2016; Accepted March 13, 2017

DOI: $10.3892 / \mathrm{mmr} .2017 .7697$

\begin{abstract}
Low molecular weight heparin (LMWH) has a structure similar to heparan sulfate, which exerts anti-inflammatory effects via inhibiting elastase (Ela) activity. Release of Ela along the glomerular capillary wall may induce glomerular injury and proteinuria. The present study aimed to investigate the influence of LMWH on steroid-sensitive nephrotic syndrome (SSNS) and the potential underlying mechanism. A total of 40 SSNS patients and 20 healthy controls were recruited. SSNS patients were treated with LMWH and prednisone simultaneously (LMWH+pred group) or with prednisone alone (pred group). Proteinuria, urinary glycosaminoglycans (GAGs), serum Ela and urinary creatinine levels were measured. The nephrotic period of SSNS was $15.93 \pm 5.78$ days. The nephrotic period of SSNS in LMWH+pred group was significantly reduced compared with the pred group $(14.13 \pm 4.56$ vs. $18.63 \pm 6.49$ days; $\mathrm{P}<0.05)$. At the follow-up of the SSNS patients, there was no statistically significant difference in number of relapses between the LMWH+pred and pred groups. Proteinuria $(2.51 \pm 0.97 \mathrm{~g} / 24 \mathrm{~h})$, urinary GAG levels $(4.92 \pm 0.87 \mathrm{mg} / \mathrm{mmol}$ creatinine) and serum Ela levels $(77.64 \pm 10.99 \mathrm{ng} / \mathrm{l})$ were significantly greater in the nephrotic period of SSNS compared with the remission period $(0.107 \pm 0.026 \mathrm{~g} / 24 \mathrm{~h}, 1.53 \pm 0.27 \mathrm{mg} / \mathrm{mmol} \mathrm{Cr}$ and $41.92 \pm 7.81 \mathrm{ng} / 1$, respectively) and the healthy control group $(0.098 \pm 0.027 \mathrm{~g} / 24 \mathrm{~h}, 1.40 \pm 0.26 \mathrm{mg} / \mathrm{mmol}$ creatinine and $38.43 \pm 9.83 \mathrm{ng} / \mathrm{l}$, respectively; $\mathrm{P}<0.05$ ). During the remission
\end{abstract}

Correspondence to: Professor Zheng Wang, Department of Pediatrics, West China Second University Hospital, Sichuan University, 20 Section 3 Renmin South Road, Chengdu, Sichuan 610041, P.R. China

E-mail: wangzheng48@21cn.com

*Contributed equally

Key words: low molecular weight heparin, primary nephrotic syndrome, steroid-sensitive nephrotic syndrome, elastase, glycosaminoglycans, proteinuria period, urinary GAG and serum Ela levels in the LMWH+pred group were significantly reduced compared with the pred group $(\mathrm{P}<0.05)$, whereas proteinuria did not differ between these groups $(\mathrm{P}>0.05)$. Positive correlations were revealed between urinary GAG excretion and proteinuria $(\mathrm{r}=0.877$; $\mathrm{P}<0.05)$, proteinuria and serum Ela levels $(\mathrm{r}=0.844 ; \mathrm{P}<0.05)$ and serum Ela levels and urinary GAG excretion ( $\mathrm{r}=0.881$; $\mathrm{P}<0.05)$. The results of the present study indicated that elevated serum Ela levels may induce proteinuria by degrading GAGs in the glomerular basement membrane in children with SSNS. LMWH may benefit nephrotic remission of SSNS via inhibiting Ela.

\section{Introduction}

Primary nephrotic syndrome (PNS) is a common renal disease in children. The majority of cases are steroid-sensitive (SSNS), the prognosis of which is good; however, patients are prone to relapse (1). The pathogenesis of PNS remains unclear; however, dysfunction of the charge-selectively of the glomerular basement membrane (GBM) may contribute to proteinuria (2). The anionic filtration of the GBM involves glycosaminoglycans (GAGs), particularly heparan sulfate proteoglycan (HSPG), a highly anionic molecule that regulates the charge- and size-selective aspects of glomerular permselectivity (3). GAGs are linear polymers of repeating amino sugar uronic acid disaccharides produced by and associated with the majority of mammalian cells and certain bacterial cells (4). GAGs may interact with numerous proteins and participate in matrix organization, cell adhesion, differentiation, growth, apoptosis and mouse kidney development $(5,6)$. Certain studies have demonstrated that reduced GAGs content in the GBM results in increased passage of proteins across the GBM, particularly negatively charged proteins $(7,8)$. Urinary GAGs levels have been suggested as a marker of glomerular damage in PNS $(9,10)$. GAGs in the GBM may be degraded by certain proteinases, including heparanase or elastase (Ela) (11). Klebanoff et al (12) revealed that Ela may degrade subendothelial matrix HSPG in vitro, which may be involved in proteinuria. By contrast, studies have demonstrated that proteinuria may be alleviated via the administration of GAGs (13-15). Low molecular weight heparin (LMWH) is a negatively charged glycoprotein due to 
$\mathrm{N}$-sulfate and O-sulfate on the carbon chain and has a similar structure to HSPG. Previous studies have revealed that the anti-inflammatory effects of LMWH were not dependent on its anticoagulant activities, but on inhibiting Ela activity and adhesion of neutrophils to vascular endothelial cells, which may have therapeutic potential for the treatment of chronic inflammatory diseases (16-18).

The influence of LMWH on urinary GAG and serum Ela levels in children with SSNS remains to be determined. Therefore, the present study used LMWH as a convenient analogue of HSPG for experimental purposes to investigate the influence of HSPG on urinary protein excretion and serum Ela levels. The results of the present study may facilitate the elucidation of the association between urinary GAGs, proteinuria and Ela.

\section{Patients and methods}

Patients and methods. Children hospitalized as a result of SSNS and healthy controls from the outpatient department, were recruited for the present study from the West China Second University Hospital (Chengdu, China) between March 2010 and July 2014. A total of 40 SSNS patients (male, $n=26$; female, $n=14$; age, $7.19 \pm 3.02$ years) and 20 sex and age-matched healthy controls (male, $n=11$; female, $n=9$; age, $7.32 \pm 3.48$ years) were included in the present study. All of the SSNS patients had PNS, as diagnosed according to the criteria from the International Study of Kidney Disease in Children (19). Urine protein excretion $>50 \mathrm{mg} / \mathrm{kg} / 24 \mathrm{~h}$ was regarded as the nephrotic state, whereas $<4 \mathrm{mg} / \mathrm{kg} / 24 \mathrm{~h}$ was regarded as the remission phase. PNS patients with complications were excluded from the present study. The coagulation function in all SSNS patients was normal. It was defined as achieving remission within 4 weeks of treatment with $2 \mathrm{mg} / \mathrm{kg} /$ day (with the majority of doses being $60 \mathrm{mg} /$ day) prednisone (pred). SSNS patients were divided into two groups, which were similar in sex and age. The LMWH+pred group $(n=24)$ was treated with pred and LMWH (30-50 IU/kg/day) simultaneously, and the pred group $(n=16)$ was treated with pred only. The two groups received similar assistant therapy, including captopril and calcium. Follow-up began on the date of diagnosis and ended in July 2014. The median follow-up was 325 days (range, 209-451 days). Regular history, physical and laboratory examinations were performed on all patients every one to two months following the disappearance of proteinuria. The present study was approved by the Institutional Review Board of West China Second University Hospital, Sichuan University (Sichuan, China), and blood and urine samples of SSNS patients and healthy controls were obtained and handled in accordance with its guidelines. The present study was performed in accordance with the ethical standards of the Declaration of Helsinki. All parents or guardians signed informed consent.

Measurement of proteinuria excretion, urinary GAG excretion and serum parameters. In SSNS patients, two urine samples were collected during the nephrotic and remission phases. In the healthy controls, one urine sample was obtained from each individual; $24 \mathrm{~h}$ urine samples were collected and stored at $-80^{\circ} \mathrm{C}$ until analysis. Urinary proteins were measured by the pyrogallol end-point method (10), while urinary GAGs excretion was examined using the modified Whiteman process $(10,11)$. GAGs levels were calculated using a calibration curve with HS as a standard, and corrected with urinary creatinine $(\mathrm{Cr})$.

At the same time, blood samples $(4 \mathrm{ml})$ were collected from SSNS patients and healthy controls and stored in tubes containing EDTA to prevent coagulation, and subsequently centrifuged at $400 \mathrm{x} \mathrm{g}$ for $5 \mathrm{~min}$ at $4^{\circ} \mathrm{C}$. Enzymatic activity of Ela was quantified by ELISA according to the manufacturer's protocols (ab119553; Abcam, London, Cambridge, UK).

Urine levels of Creatinine $(\mathrm{Cr})$ were measured using an Hitachi 7600 Chemistry Analyzer (Hitachi, Ltd., Tokyo, Japan).

Statistical analysis. All statistical analyses were performed in SPSS software version 17.0 (SPSS, Inc., Chicago, IL, USA). Continuous data were presented as the mean \pm standard deviation. Comparison of continuous data was performed with an independent t-test between the two groups, whereas the correlation among categorical variables was analyzed by a two-sided Chi-square test. Multiple groups were compared using one way Analysis of variance. Spearman's test was used to analyze correlations. $\mathrm{P}<0.05$ was considered to indicate a statistically significant difference.

\section{Results}

Patient clinical profile. A total of 40 children hospitalized with SSNS and 20 healthy controls were enrolled in the present study. The clinical characteristics of the participants are presented in Table I. Of the 40 SSNS patients, 25 patients had an infection history 7 to 14 days prior to the diagnosis of nephrotic syndrome (upper respiratory tract infection, $\mathrm{n}=6$; acute tonsillitis, $\mathrm{n}=10$; bronchitis, $\mathrm{n}=5$; pneumonia, $\mathrm{n}=4$; Fig. 1A). In the pred group, 10 patients had an infection (upper respiratory tract infection, $n=2$; acute tonsillitis, $n=5$; bronchitis, $\mathrm{n}=2$; pneumonia, $\mathrm{n}=1$ ). In the LMWH+pred group, 15 patients had an infection (upper respiratory tract infection, $\mathrm{n}=3$; acute tonsillitis, $\mathrm{n}=7$; bronchitis, $\mathrm{n}=3$; pneumonia, $\mathrm{n}=2$ ).

The nephrotic period of SSNS was $15.93 \pm 5.78$ days (range, 6-27 days). The nephrotic period of SSNS in the LMWH+pred group was $14.13 \pm 4.56$ days, which was significantly reduced compared with the pred group (18.63 \pm 6.49 days, Table I).

All patients were followed up for an average of 325 days (range from 209 to 451 days). During the follow-up period, there were 31 relapse cases of SSNS. Of these cases, 3 were of frequent relapse; one in the LMWH+pred group, whose renal pathology indicated minimal change disease, and two in the pred group, whose renal pathology indicated minimal change disease and focal segmental glomerulosclerosis. As presented in Fig. 1B, the 31 relapse cases of SSNS were suspected to be the result of infection $(n=21,67.7 \%)$, reducing pred dose $(n=7,22.6 \%)$ or no clear reason $(n=3,9.7 \%)$. In the 18 relapse patients in the LMWH+pred group, the suspected factors were infection $(n=12,66.7 \%)$, reducing pred dose $(n=4,22.2 \%)$ or no clear reason $(n=2,11.1 \%)$. In the 13 relapse patients in the pred group, the suspected factors were infection $(n=9,69.2 \%)$, reducing pred dose $(n=3,23.1 \%)$ or no clear reason $(n=1,7.7 \%)$. There was no statistically significant difference in number of relapses between the LMWH+pred and pred groups $(\mathrm{P}>0.05$, Table I). 
Table I. Clinical profiles of 40 SSNS patients and 20 healthy controls.

\begin{tabular}{|c|c|c|c|c|c|c|}
\hline \multirow[b]{2}{*}{ Parameter } & \multicolumn{4}{|c|}{ SSNS patients $(\mathrm{n}=40)$} & \multicolumn{2}{|c|}{ Healthy controls $(n=20)$} \\
\hline & Pred $(n=16)$ & LMWH+pred $(\mathrm{n}=24)$ & P-value & All SSNS $(n=40)$ & All control $(n=20)$ & P-value \\
\hline Age (years) & $7.43 \pm 3.52$ & $7.02 \pm 2.69$ & $0.092^{\mathrm{a}}$ & $7.19 \pm 3.02$ & $7.32 \pm 3.48$ & $0.214^{\mathrm{a}}$ \\
\hline Gender & & & $0.685^{\mathrm{b}}$ & & & $0.453^{\mathrm{b}}$ \\
\hline Male & $11(68.8 \%)$ & $15(62.5 \%)$ & & $26(65.0 \%)$ & $11(55 \%)$ & \\
\hline Female & $5(31.2 \%)$ & $9(37.5 \%)$ & & $14(35.0 \%)$ & $9(45 \%)$ & \\
\hline Respiratory infection & & & $1^{\mathrm{b}}$ & & & l \\
\hline No & $6(37.5 \%)$ & $9(37.5 \%)$ & & $15(37.5 \%)$ & 0 & \\
\hline Yes & $10(62.5 \%)$ & $15(62.5 \%)$ & & $25(62.5 \%)$ & 0 & \\
\hline LMWH & & & l & & & I \\
\hline No & $16(100 \%)$ & $0(0 \%)$ & & $16(40 \%)$ & 0 & \\
\hline Yes & $0(0 \%)$ & $24(100 \%)$ & & $24(60 \%)$ & 0 & \\
\hline Relapse & & & $0.643^{\mathrm{b}}$ & & & I \\
\hline No & $3(18.8 \%)$ & $6(25.0 \%)$ & & $9(22.5 \%)$ & 0 & \\
\hline Yes & $13(81.2 \%)$ & $18(75.0 \%)$ & & $31(77.5 \%)$ & 0 & \\
\hline $\begin{array}{l}\text { Nephrotic period } \\
\text { (days) }\end{array}$ & $18.63 \pm 6.49$ & $14.13 \pm 4.56$ & $0.014^{\mathrm{a}}$ & $15.93 \pm 5.78$ & 0 & \\
\hline
\end{tabular}

Data for age and nephrotic period are presented as the mean \pm standard deviation. ${ }^{\mathrm{a} C a l c u l a t e d}$ with an independent t-test; ${ }^{\mathrm{b}} \mathrm{calculated}$ with a two-sided Chi-square test. Pred, prednisone; LMWH, low molecular weight heparin; SSNS, steroid-sensitive nephrotic syndrome.
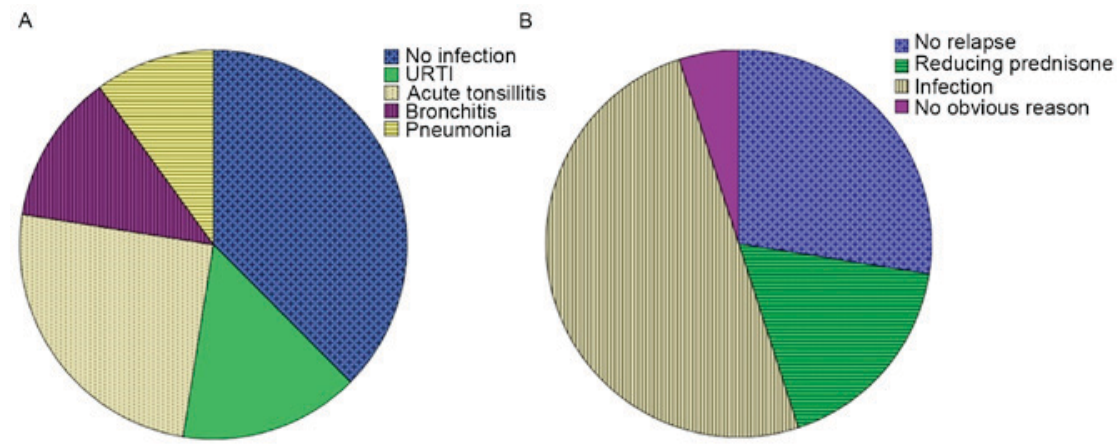

Figure 1. (A) Distribution of potential inducing factors in SSNS patients and (B) the reasons for relapse. URTI, upper respiratory tract infection.

Proteinuria in $24 \mathrm{~h}$. As presented in Fig. 2, proteinuria in the nephrotic period of SSNS $(2.51 \pm 0.97 \mathrm{~g} / 24 \mathrm{~h})$ was significantly greater compared with the remission period of SSNS $(0.107 \pm 0.026 \mathrm{~g} / 24 \mathrm{~h})$ and the healthy control group $(0.098 \pm 0.027 \mathrm{~g} / 24 \mathrm{~h}, \mathrm{P}<0.05)$, whereas proteinuria was not significantly different between the remission period of SSNS and the healthy control group ( $\mathrm{P}>0.05$, Fig. 2A). In the nephrotic period of SSNS, proteinuria in the LMWH+pred group was similar to the pred group $(2.62 \pm 0.99 \mathrm{~g} / 24 \mathrm{~h}$ vs. $2.34 \pm 0.94 \mathrm{~g} / 24 \mathrm{~h}, \mathrm{P}>0.05$, Fig. $2 \mathrm{~B})$. In the remission period of SSNS, there were no significant differences in proteinuria between the LMWH+pred $(0.102 \pm 0.024 \mathrm{~g} / 24 \mathrm{~h})$, pred $(0.114 \pm 0.029 \mathrm{~g} / 24 \mathrm{~h})$ and healthy control groups (0.098 \pm 0.027 g/24 h, P>0.05, Fig. 2C).

Urinary GAG excretion in $24 h$. The results of urinary GAG excretion were corrected by the ratio of urinary GAGs (UGAGs) to urinary $\mathrm{Cr}$ (UCr). As presented in Fig. 3, in SSNS patients the ratio of $\mathrm{UGAGs} / \mathrm{UCr}$ in the nephrotic period $(4.92 \pm 0.76 \mathrm{mg} / \mathrm{mmol} \mathrm{Cr})$ was significantly greater compared with the remission period $(1.39 \pm 0.14 \mathrm{mg} / \mathrm{mmol} \mathrm{Cr})$ and the healthy control group $(1.37 \pm 0.10 \mathrm{mg} / \mathrm{mmol} \mathrm{Cr}$; $\mathrm{P}<0.05)$, whereas the ratio of $\mathrm{UGAGs} / \mathrm{UCr}$ in the remission period was similar to the control group ( $\mathrm{P}>0.05$; Fig. 3A). Comparison of the LMWH+pred and pred groups revealed no significant difference in the ratio of UGAGs/UCr in the nephrotic period (4.95 \pm 0.71 vs. $4.89 \pm 0.85 \mathrm{mg} / \mathrm{mmol} \mathrm{Cr}$; P>0.05; Fig. 3B). In the remission period, the ratio of $\mathrm{UGAGs} / \mathrm{UCr}$ in the $\mathrm{LMWH}+$ pred group was significantly reduced compared with the pred group $(1.36 \pm 0.12$ vs. $1.45 \pm 0.15 \mathrm{mg} / \mathrm{mmol} \mathrm{Cr}$; $\mathrm{P}<0.05)$, whereas these two groups were not significantly different compared with the healthy control group ( $\mathrm{P}>0.05$; Fig. $3 \mathrm{C}$ ). Therefore, following steroid therapy in SSNS patients, there was a significant reduction in GAG excretion, and pred accompanied by LMWH treatment was more efficient in reducing urinary GAGs excretion compared with pred monotherapy. 


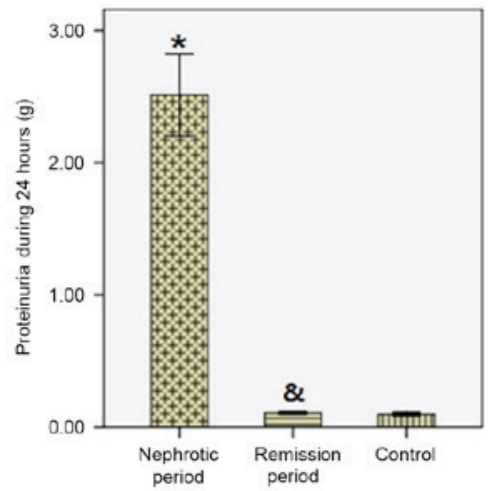

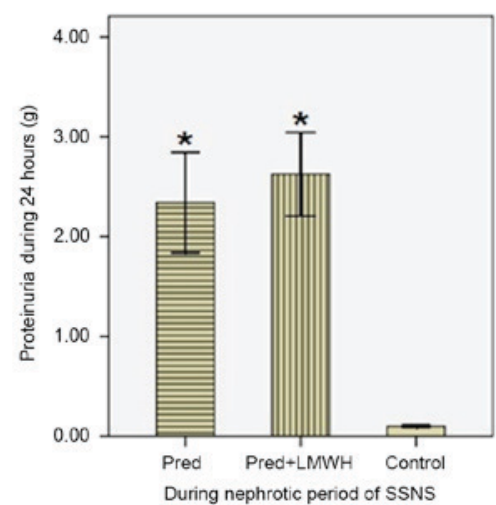

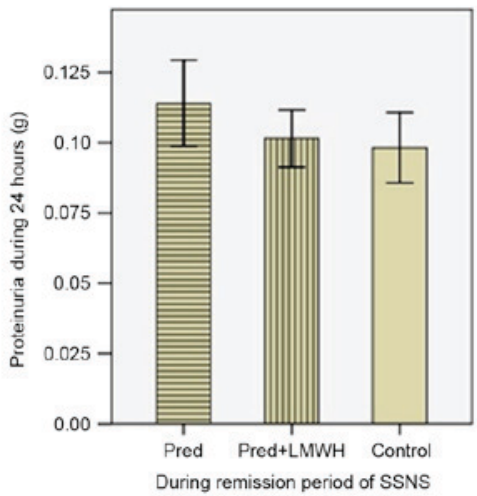

Figure 2. Proteinuria in $24 \mathrm{~h}$. (A) Effect of treatment in SSNS patients compared with healthy controls. Proteinuria during the (B) nephrotic and (C) remission periods of SSNS. "P<0.05 vs. control; ${ }^{*} \mathrm{P}<0.05$ vs. nephrotic period. Pred, prednisone; LMWH, low molecular weight heparin; SSNS, steroid-sensitive nephrotic syndrome.
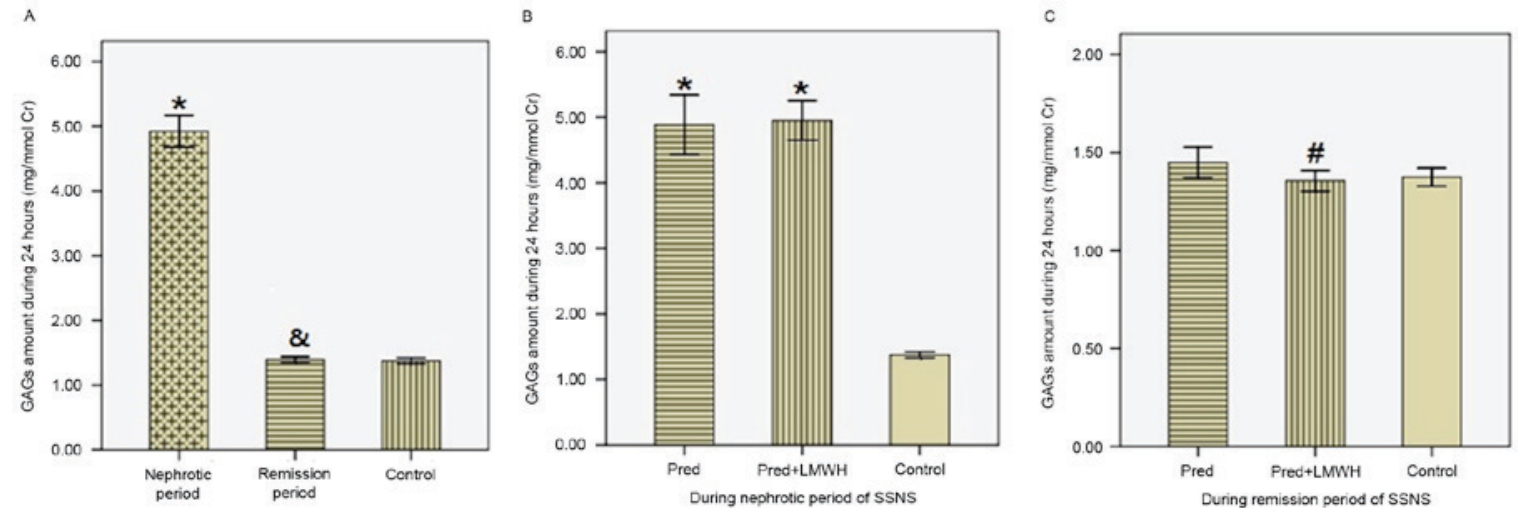

Figure 3. Urinary GAG excretion in $24 \mathrm{~h}$. (A) Effect of treatment in SSNS patients compared with healthy controls. Urinary GAG excretion during the (B) nephrotic and (C) remission periods of SSNS. " $\mathrm{P}<0.05$ vs. control; ${ }^{\circ} \mathrm{P}<0.05$ vs. nephrotic period; ${ }^{*} \mathrm{P}<0.05$ vs. pred. Pred, prednisone; LMWH, low molecular weight heparin; SSNS, steroid-sensitive nephrotic syndrome; GAG, glycosaminoglycan; Cr, creatinine.

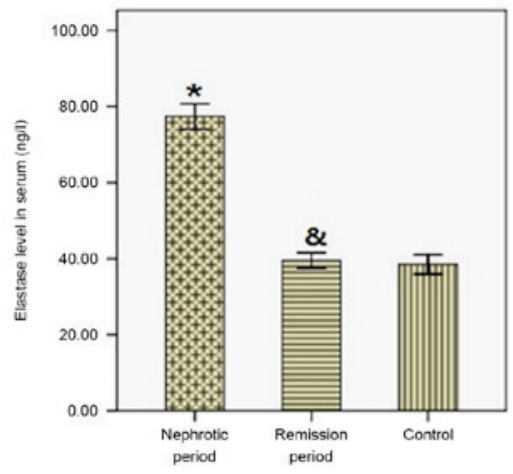

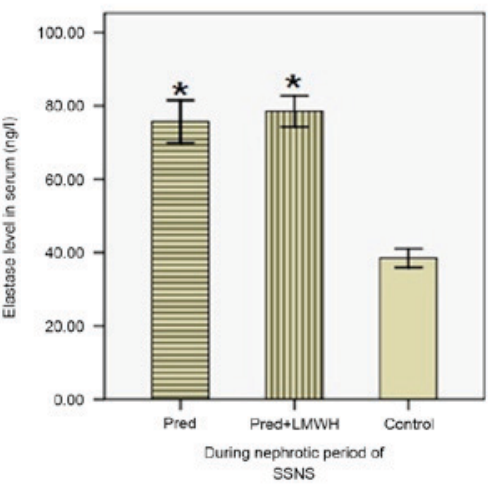

c

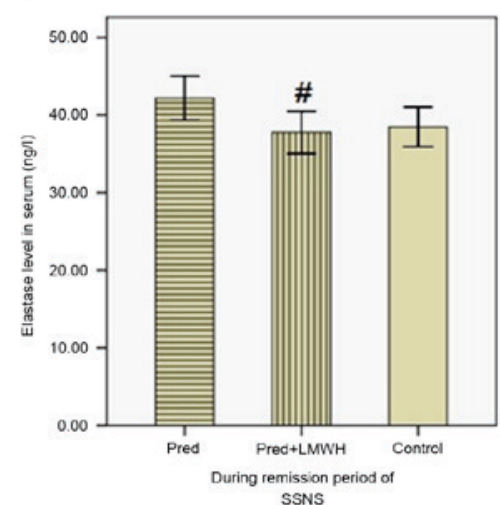

Figure 4. Serum elastase levels. (A) Effect of treatment in SSNS patients compared with healthy controls. Serum levels of elastase during the (B) nephrotic and (C) remission periods of SSNS. "P $<0.05$ vs. control; ${ }^{\&} \mathrm{P}<0.05$ vs. nephrotic period; ${ }^{\#} \mathrm{P}<0.05$ vs. pred. Pred, prednisone; LMWH, low molecular weight heparin; SSNS, steroid-sensitive nephrotic syndrome.

Serum Ela levels. As presented in Fig. 4, serum Ela levels in the nephrotic period $(77.39 \pm 10.38 \mathrm{ng} / \mathrm{l})$ were significantly greater compared with the remission period $(39.55 \pm 6.35 \mathrm{ng} / 1, \mathrm{P}<0.05)$ and the healthy control group $(38.48 \pm 5.44 \mathrm{ng} / \mathrm{l}, \mathrm{P}<0.05)$, whereas Ela levels in the remission period were similar to those in the control group (Fig. 4A). Ela levels were not significantly different between the LMWH+pred and pred group during the nephrotic period $(78.53 \pm 10.05$ vs. $75.69 \pm 10.96 \mathrm{ng} / \mathrm{l}, \mathrm{P}>0.05$, Fig. 4B). In the remission period, Ela levels in the LMWH+pred group were significantly reduced compared with the pred group $(37.78 \pm 6.49$ vs. $42.20 \pm 5.28 \mathrm{ng} / 1, \mathrm{P}<0.05)$, whereas these two groups were not significantly different compared with the 
A

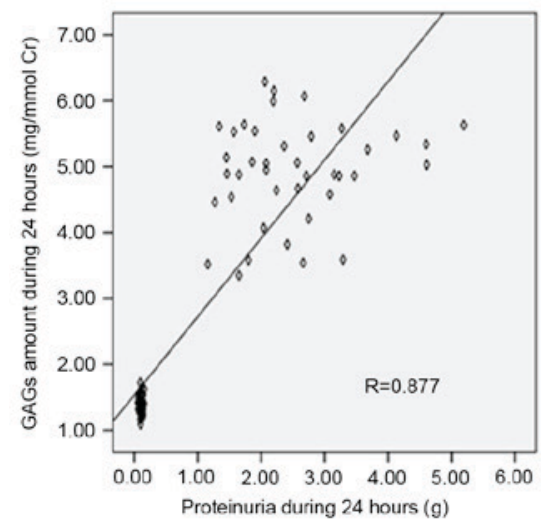

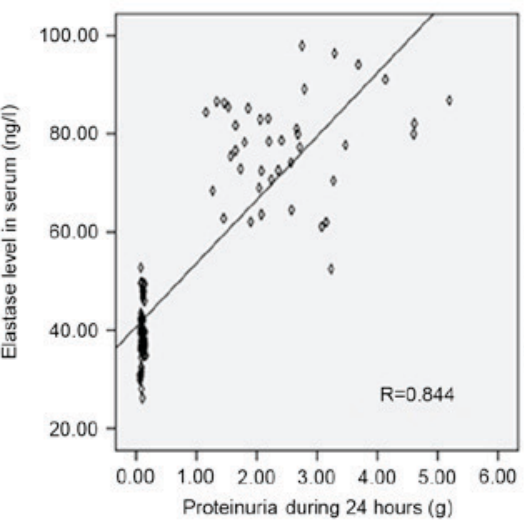



Figure 5. Correlations between urinary GAG excretion, proteinuria and serum elastase levels. Correlation between (A) urinary GAG levels and proteinuria, (B) serum elastase levels and proteinuria and (C) serum elastase levels and urinary GAG excretion. GAG, glycosaminoglycan; Cr, creatinine.

healthy control group ( $\mathrm{P}>0.05$, Fig. 4C). Therefore, following steroid therapy in SSNS patients, there was a significant reduction in serum Ela levels, and pred accompanied by LMWH treatment was more efficient in reducing serum Ela levels compared with pred monotherapy.

Association between urinary GAG excretion, proteinuria and serum Ela levels. Correlation analysis of all participants revealed significant positive correlations between urinary GAG levels and proteinuria ( $\mathrm{r}=0.877, \mathrm{P}<0.05$, Fig. 5A), serum Ela levels and proteinuria $(r=0.844, \mathrm{P}<0.05$, Fig. $5 \mathrm{~B})$, and serum Ela and urinary GAG levels $(r=0.881, \mathrm{P}<0.05$, Fig. 5C).

\section{Discussion}

The results of the present study suggested that pred and LMWH treatment reduced proteinuria and urinary GAGs levels and decreased the nephrotic period in SSNS patients, but had no effect on SSNS relapse.

It had previously been reported that the GAGs content of GBM was reduced in nephrotic syndrome and that this decrease in GAGs induced the loss of the GBM negative charge, which might contribute to an increase in urinary proteins $(20,21)$. Girardin et al suggested that various lymphocytic factors may decrease the anionic charge of the GBM, and so increase permeability to albumin (22). Mitsuhashi et al (23) investigated adult patients with minimal change disease and revealed that they excreted significantly greater levels of HSPG compared with controls. Consistent with these results, in child SSNS patients, the present study detected elevated levels of urinary GAGs excretion during the nephrotic period and normal levels during the remission period. Heeringa et al (24) reported that in rats, renal perfusion with Ela might induce proteinuria by GBM HSPG degradation. Our previous studies of rats infected with respiratory syncytial virus (RSV) indicated that RSV might induce renal minimal change similar to human minimal change disease, and degradation of GAGs on GBM potentially via elevated heparanase and Ela (25-27). The present study demonstrated that LMWH administration may reduce excretion of urinary proteins and that pred accompanied by LMWH treatment was more efficient compared with pred monotherapy in reducing nephrotic period and urinary GAGs excretion, and decreasing the level of serum Ela. Previous studies have reported that LMWH may inhibit the release of Ela from human neutrophils $(28,29)$. Therefore, LMWH may be beneficial in SSNS via inhibiting Ela and reducing degradation of GBM GAGs. The present study also revealed that LMWH had no preventive and predictive effect on the relapse of SSNS.

In conclusion, the results of the present study indicated that urinary excretion of GAGs was associated with the degree of proteinuria and serum Ela levels in children with SSNS. Treatment with LMWH may benefit proteinuria remission.

\section{Acknowledgements}

The present study was supported in part by the National Natural Science Foundation of China (grant no. 81370807). The authors thank Dr Nan Li (College of Preclinical and Forensic Medicine, Sichuan University) for language checking and proofreading the manuscript.

\section{References}

1. Working Group For National Survey On Status Of Diagnosis And Treatment Of Childhood Renal Diseases: Multicenter survey of diagnostic and therapeutic status in Chinese childhood patients with steroid-sensitive, relaping/steroid-dependent nephrotic syndrome. Zhonghua Er Ke Za Zhi 52: 194-200, 2014 (In Chinese).

2. Brenner BM, Hostetter TH and Humes HD: Glomerular permselectivity: Barrier function based on discrimination of molecular size and charge. Am J Physiol 234: F455-F460, 1978.

3. Bridges CR, Myers BD, Brenner BM and Deen WM: Glomerular charge alterations in human minimal change nephropathy. Kidney Int 22: 677-684, 1982.

4. Miner JH: Renal basement membrane components. Kidney Int 56: 2016-2024, 1999.

5. Yamada T and Kawasaki T: Microbial synthesis of hyaluronan and chitin: New approaches. J Biosci Bioeng 99: 521-528, 2005.

6. Davies JA, Fisher CE and Barnett MW: Glycosaminoglycans in the study of mammalian organ development. Biochem Soc Trans 29: 166-171, 2001.

7. Cengiz N, Bayazit AK, Noyan A, Anarat R and Anarat A: Glycosaminoglycan excretion in children with nephrotic syndrome. Pediatr Nephrol 20: 486-490, 2005.

8. Carrie BJ, Salyer WR and Myers BD: Minimal change nephropathy: An electrochemical disorder of the glomerular membrane. Am J Med 70: 262-268, 1981. 
9. Baggio B, Gambaro G, Briani G, Favaro S and Borsatti A: Urinary excretion of glycosaminoglycans and brush border and lysosomal enzymes as a marker of glomerular and tubular involvement in kidney disease. Contrib Nephrol 42: 107-110, 1984.

10. Hotz P, Pilliod J, Berode M, Rey F and Boillat MA: Glycosaminoglycans, albuminuria and hydrocarbon exposure. Nephron 58: 184-191, 1991.

11. Liu XM, Wang Z and Guo Y: Respiratory syncytial virus nephropathy in rats. Kidney Int 71: 388-396, 2007.

12. Klebanoff SJ, Kinsella MG and Wight TN: Degradation of endothelial cell matrix heparan sulfate proteoglycan by elastase and the myeloperoxidase- $\mathrm{H}_{2} \mathrm{O}_{2}$-chloride system. Am J Pathol 143 907-917, 1993

13. Baggio B and Gambaro G: Antiproteinuric effect of glycosaminoglycans? Nephron 64: 643-644, 1993.

14. Vehaskari VM, Root ER, Germuth FG Jr and Robson AM Glomerular charge and urinary protein excretion: Effect of systemic and intrarenal polycation infusion in the rat. Kidney Int 22: 127-135, 1982

15. Chen S-J, Zhang S-W, Wei M, Xiong Y, Gao Y, Hu Y, et al: Glycosaminoglycans on CRP and UAER of early diabetic nephropathy. Zhong Guo Lao Nian Xue Za Zhi 27: 1779-1781, 2007 (In Chinese)

16. Lever R and Page CP: Novel drug development opportunities for heparin. Nat Rev Drug Discov 1: 140-148, 2002.

17. PAGE CP: One explanation of the asthma paradox: Inhibition of natural anti-inflammatory mechanism by beta 2 -agonists Lancet 337: 717-720, 1991.

18. Brown RA, Leung E, Kankaanranta H, Moilanen E and Page CP: Effects of heparin and related drugs on neutrophil function. Pulm Pharmacol Ther 25: 185-192, 2012.

19. Birmele B, Thibault G, Nivet H, de Agostini A and Girardin EP In vitro decrease of glomerular heparan sulfate by lymphocytes from idiopathic nephrotic syndrome patients. Kidney Int 59: 913-922, 2001

20. Salant DJ: The structural biology of glomerular epithelialcells in proteinuric diseases. Curr Opin Nephrol Hypertens 3: 569-574, 1994.
21. Vernier RL, Klein DJ, Sisson SP, Mahan JD, Oegema TR and Brown DM: Heparan sulphate-rich anionic sites in the human glomerular basement membrane. Decreased concentration in congenital nephrotic syndrome. N Engl J Med 309: 1001-1009, 1983 .

22. Girardin EP, Birmele B, Benador N, Neuhaus T, Hosseini G, Van Den Heuvel LP and De Agostini A: Effect of plasma from patients with idiopathic nephrotic syndrome on proteoglycan synthesis by human and rat glomerular cells. Pediatr Res 43: 489-495, 1998.

23. Mitsuhashi H, Tsukada Y, Ono K, Yano S and Naruse T: Urine glycosaminoglycans and heparan sulfate excretions in adult patients with glomerular diseases. Clin Nephrol 39: 231-238, 1993.

24. Heeringa P, Van den Born J, Brouwer E, Dolman KM, Klok PA, Huitema MG, Limburg PC, Bakker MA, Berden JH, Daha MR and Kallenberg CG: Elastase, but not proteinase 3 (PR3), induces proteinuria associated with loss of glomerular basement membrane heparan sulphate after in vivo renal perfusion in rats. Clin Exp Immunol 105: 321-329, 1996.

25. Guo Y, Wang Z, Dong L, Wu J, Zhai S and Liu D: Ability of low-molecular-weight heparin to alleviate proteinuria by inhibiting respiratory syncytial virus infection. Nephrology (Carlton) 13: 545-553, 2008

26. Tao YH, Wang Z and Zhou YR: Expression of heparanase in kidney of rats with respiratory syncytial virus nephropathy and its relationship with proteinurina. Sichuan Da Xue Xue Bao Yi Xue Ban 45: 212-224, 2014 (In Chinese).

27. Dong LQ, Wang XQ, Guo YN, Wu J, Li S, Yu P and Wang Z: HS N-sulfation and iduronic acids play an important role in the infection of respiratory syncytial virus in vitro. Eur Rev Med Pharmacol Sci 17: 1864-1868, 2013.

28. Brown RA, Lever R, Jones NA and Page CP: Effects of heparin and related molecules upon neutrophil aggregation and elastase release in vitro. Br J Pharmacol 139: 845-853, 2003.

29. Cadène M, Boudier C, de Marcillac GD and Bieth JG: Influence of low molecular mass heparin on the kinetics of neutrophil elastase inhibition by mucus proteinase inhibitor. J Biol Chem 270: 13204-13209, 1995. 